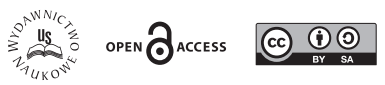

„Analiza i Egzystencja” 56 (2021), 25-52

ISSN (print): 1734-9923

ISSN (online): 2300-7621

DOI: $10.18276 /$ aie.2021.56-02

ARTYKUŁY

MONIKA MICHAŁOWSKA *

ORCID: 0000-0001-9415-389X

ŁUKASZ KOWALCZYK

ORCID: 0000-0003-0886-763X

WERONIKA MARCINKOWSKA

ORCID: 0000-0001-7427-6809

MIKOŁAJ MALICKI

ORCID: 0000-0001-8863-1218

* Monika Michałowska - University Professor at the Department of Bioethics, Medical University of Łódź, Poland. Her research focuses on bioethical aspects of reproductive medicine, feminist approaches to issues such as preimplantation genetic diagnosis, gamete and mitochondrial donation, as well as human enhancement and ethics of neural technologies. In her research, she combines cross disciplinary approaches to bioethical problems (bioethics/film studies/cultural studies/body, bio and cyborg art).

Address for correspondence: Medical University of Łódź, Department of Bioethics, Lindleya 6, 90-130 Łódź, Poland. E-mail: monika.michalowska@umed.lodz.pl.

Łukasz Kowalczyk - Assistant at the Department of Bioethics, Medical University of Łódź, Poland, MD, current postgraduate student of bioethics at Warsaw University. His research in fields of psychiatry and neurology focuses on ethical issues they generate. He works on medical and bioethical contexts of the use of virtual reality, neurostimulation, and brain computer interfaces, concentrating on sense of agency and autonomy.

Address for correspondence: Medical University of Łódź, Department of Bioethics, Lindleya 6, 90-130 Łódź, Poland. E-mail: lukasz.kowalczyk@umed.lodz.pl.

Weronika Marcinkowska - student at Faculty of Medicine at Medical University of Łódź. Her research focuses on bacteriology and anatomy.

Mikołaj Malicki - student at Faculty of Medicine at Medical University of Łódź. His research clusters around angiology and microbiology. 


\title{
BEING OUTSIDE THE DECISION-LOOP: THE IMPACT OF DEEP BRAIN STIMULATION AND BRAIN-COMPUTER INTERFACES ON AUTONOMY
}

\begin{abstract}
Keywords: neural technologies, autonomy, control, decision-making, well-being, informed consent

Słowa kluczowe: neurotechnologie, autonomia, kontrola, decyzyjność, dobrostan, zgoda świadoma
\end{abstract}

Technology is a natural extension and expression of human intellect and will, of creativity, curiosity, and imagination. We foresee and encourage the development of ever more flexible, smart, responsive technology. We will co-evolve with the products of our minds, integrating with them, finally merging with our intelligent technology in a posthuman synthesis, amplifying our abilities and extending our freedom.

(More, 1995)

\section{Introduction}

Recent advancements in developing clinically more effective and technologically more reliable neuro-interventions have added new problems and dimensions to an already intense debate on the ethical aspects of using novel neural technologies, such as deep brain stimulation (DBS) and braincomputer interfaces (BCIs). The application of DBS and BCIs has triggered a discussion on whether they pose a threat to personal autonomy. The prevalent stance in the literature is that such interventions are invasive, potentially harmful, and addictive or seductive, and that they may deleteriously affect people's choices, selves, authenticity, and sense of agency. Some authors seek to provide sets of risks and offer categorizations of the threats the new technologies allegedly pose to us as individuals and societies (O'Brolcháin et al., 2015).

While we agree that any medical novelty involves uncertainty as to how (much) it may alter the way we live, understand the self, and make sense of the world around us, uncertainty and the unknown are in fact 
embedded in the definition of change. This does not necessarily entail, however, that such an alteration or a transition will cause us harm or bring detrimental outcomes. The domain of bio-, neuro-, and genetic-technologies has already proved especially susceptible to stereotypes and biases concerning human nature. Some bioethicists and philosophers call for protecting our genetic legacy, autonomy, and the self, wherein they perceive medical novelties as a threat and evaluate new medical technologies in the framework of anthropocentric beliefs underpinned by an explicitly or implicitly articulated precautionary principle. We are quite regularly warned that

[o]ne aspect of our humanity that might be threatened by enhancement and genetic engineering is our capacity to act freely, for ourselves, by our own efforts, and to consider ourselves responsible - worthy of praise or blame - for the things we do and for the way we are.

(Sandel, 2007, p. 25)

In the case of DBS and BCIs, two aspects add to the complexity of this picture. One of them is related to the fact that some neural implants (brain implants) based on closed-loop systems operate automatically, and involves a concern that DBS and BCIs may diminish or entirely eliminate personal autonomy. While such misgivings are quite commonly voiced, they dangle in the definitional void, as it is unclear what notion of autonomy is actually adopted by the authors. Apart from a handful of authors who proceed with definitional care and precision (Friedrich, Racine, Steinert, Pömsl, Jox, 2021; Kellmeyer et al., 2016; Pugh, Pycroft, Sandberg, Aziz, Savulescu, 2018), most papers on this issue implicitly embrace a rather vague notion of autonomy, which comes down to a cluster of terms conventionally associated with an autonomous agent, such as control, freedom, and independence (Burwell, Sample, Racine, 2017; Gilbert, Cook, O’Brien, Illes, 2019; Iwry, Yaden, Newberg, 2017; Maynard, Scragg, 2019; Wolkenstein, Jox, Friedrich, 2018; Yuste et al., 2017). Although we are indeed warned that we may lose something, we are not told what that something is. Instead, the terminology of "being in control" and "free decision-making" is employed as a supposedly sufficient argument for the claim that the loss of control/ freedom of decision-making equals the loss of autonomy. This reductive understanding seems to be a gross simplification of a rather important issue in the debate. The other narrative element of the debate on DBS and BCIs is the focus on autonomy as the supreme value, which dominates the discourse 
to such an extent that other essential values seem to be disappearing from the bioethical horizon, becoming less valued, less important, and less visible.

Below, we shall look into these two notions - control and free decision making - construed as the key features of an autonomous agent, and argue that constant and total control and/or an absolute freedom of decision-making are not the necessary conditions of autonomy. In our reasoning, we shall build on the notion of well-being in its philosophical context, in particular on desire-based theory, which accentuates the value of desire-satisfaction as the cornerstone of personal well-being. Flourishing, having one's desires fulfilled, and being the author of one's own life-biography are, in our view, important factors in well-being. We shall marshal them to redirect the current debate on the bioethical aspects of neural technologies from the prevailing autonomy-threat perspective to one that accommodates other essential values as well.

Since medical and technical aspects of neural technologies are important to understand our argument, we shall begin by outlining the medical background of BCIs/DBS applications and the difference between the openloop and closed-loop systems. This will offer some insight into how their medical effects improve patients' condition and quality of life, which we shall briefly discuss while addressing the autonomy-problem in one of the sections below.

\section{The Medical Background of BCIs/DBS Applications}

Although neural technologies have been in use for quite some time now, the rapid development and modifications of devices such as brain-computer interfaces and direct neurostimulation open a new platform for their application (Batista, 2020; Edwards, Kouzani, Lee, Ross, 2017; Lahr et al., 2015; Leeb, Pérez-Marcos, 2020). BCIs employ intracortical sensors, decoder algorithms, and translators to record, analyze, and convert real-time brain activity into particular information (Davidoff, 2020; Kawala-Sterniuk et al., 2021; Thinnes-Elker et al., 2012). The collected data is processed into commands which control an external device (such as a robotic arm) "just by thinking about the movement" (Glannon, 2016, p. 11), or via wireless communicational systems (McGie, Nagai, Artinian-Shaheen, 2013). The benefits of the restoration of motor and articulation functions have already demonstrated the 
prospects for improving the quality of life of patients with severe, chronic, and terminal illnesses (Belkacem, Jamil, Palmer, Ouhbi, Chen, 2020).

Brain-computer interfaces and neurostimulation devices are designed as open- or closed-loop systems (Potter, El Hady, Fetz, 2014; Sisterson, Kokkinos, 2020; Sun, Morrell, 2014; Vassileva, van Blooijs, Leijten, Huiskamp, 2018; Zhou, Chen, Farber, Shetter, Ponce, 2018). In an open-loop system, the operations of external devices and neurostimulation parameters, such as frequency, amplitude, and duty cycle, are primarily pre-set at the beginning of treatment (Ghasemi, Sahraee, Mohammadi, 2018). A physician can regulate and readjust them based on a patient's outcomes and condition, while the patient can actively participate in decision-making on how to act after receiving information from the device (e.g., via audio or light signals; Kellmeyer et al., 2016). Although this approach aims to maximize treatment effectiveness and minimize possible side effects (Ghasemi et al., 2018), it does not permit an efficient response or adaptation to dynamic changes of the system-parameters. Also, open-loop systems are associated with the risk of hypostimulation and hyperstimulation (Glannon, 2016), and thus patients may require additional hospitalizations in order to fine-tune the parameters of the devices. Moreover, patients' active involvement in the therapeutic process (which produces additional risks of non-compliance with medical recommendations) can increase the incidence of device malfunction.

In contrast, dynamically developing closed-loop systems receive continuous information input from the patient's brain, which enables them to adjust the parameters on their own through a programmed algorithm. They rely on feedback and automatic control to reduce error (Jianhong, RamirezMendoza, 2020) and excessive, burdensome patient-involvement in decisionmaking. Medical reports describe successful applications of BCIs and DBS systems in the treatment of numerous neurological and psychiatric diseases, such as neurodegenerative disorders and traumatic brain and spinal cord injuries (Burwell et al., 2017; Kellmeyer, Grosse-Wentrup, Schulze-Bonhage, Ziemann, Ball, 2018; Klein, 2020; Marchetti, Priftis, 2015; Vansteensel, Jarosiewicz, 2020; Vaughan, 2020; Zheng, Mao, Yuan, Xu, Cheng, 2020). There is a preference for closed-loop systems in some cases. For example, Parkinson's patients have exhibited a significantly greater symptom reduction with closed-loop than with open-loop systems (Ghasemi et al., 2018). This may be related to the unidirectionality of open-loop systems, which do not adapt to the changing needs of the patients' brains (Klein, 2020). 
Besides BCIs, deep brain stimulation is a nascent and rapidly developing therapeutic technique in psychiatry and neurology (Aum, Tierney, 2018; Dougherty, 2018). The system uses unilateral or bilateral electrodes, which are implanted into the brain under neuroimaging control (Glannon, 2016; Steigerwald, Matthies, Volkmann, 2019). The electrodes modulate the function of the nodes of the neural circuits (the dysfunctional area of the brain) (Glannon, 2016). Electrical stimulation is generated by a device implanted subcutaneously in the clavicle or the abdomen (White-Dzuro, Lake, Neimat, 2017). The stimulation parameters are modulated manually by the therapist, or automatically by closed-loop devices (Habets et al., 2018; Neumann et al., 2019). DBS systems are used in a number of neurological and psychiatric diseases, including epileptic seizures (Klinger, Mittal, 2018; Yan et al., 2018), Parkinson's disease (Kogan, McGuire, Riley, 2019; Malek, 2019), dystonia (Rodrigues, Duarte, Prescott, Ferreira, Costa, 2019), essential tremor (Lake, Hedera, Konrad, 2019), Tourette's syndrome (Xu et al., 2020), major depressive disorder (Drobisz, Damborská, 2019), obsessive-compulsive disorder (Arya, Filkowski, Nanda, Sheth, 2019), eating disorders (Dalton, Bartholdy, Campbell, Schmidt, 2018; Lipsman et al. 2013), and addictive disorders (Rachid, 2018). Neurostimulation reduces bothersome symptoms, improves motor functions, cures drug-resistant affective disorders and obsessions, and in this way stimulates the recovery of mental and physical homeostasis.

\section{The Concepts of Autonomy}

All medical novelties tie in with the issue of autonomy, especially if they are invasive and/or involve technological or genetic body modifications. While Joel Feinberg's arresting claim "I am autonomous if I rule me, and no one else rules I" (Feinberg, 1980, p. 21) apparently raises no doubts as to what an autonomous person is, it sparks controversies over the actual meaning of "to rule," the range of autonomy and ruling ascribed to a person, and the definition of the "I." Besides, it merely proposes one of many approaches in this multifaceted dispute, rather than giving a clear insight into autonomy. Admittedly, the same is true for all the theories of autonomy in philosophy and bioethics, which contributes to the fact that the debate on autonomy has polarized philosophers and bioethicists, fueling the proliferation of concepts and theories, and even prompting some feminist philosophers to denounce 
the concept as oppressive (Dworkin, 1988, pp. 3-13; Mackenzie, Stoljar, 2000; Mele, 1995; Meyers, 1987; O’Neill, 2002, pp. 21-27).

Paradoxically, although approaches to autonomy vary, they invariably put a premium value on autonomy, and to some philosophers it even overrides other values (Nozick, 1974). Autonomy is commonly considered one of the key features that make us moral agents and bespeak our personhood. While the ongoing vigorous debate offers a wide range of claims and arguments, some common characteristics of autonomy are usually evoked. As John Christman puts it:

$[\mathrm{T}] \mathrm{o}$ be autonomous is to govern oneself, to be directed by considerations, desires, conditions, and characteristics that are not simply imposed externally upon one, but are part of what can somehow be considered one's authentic self. Autonomy in this sense seems an irrefutable value, especially since its opposite - being guided by forces external to the self and which one cannot authentically embrace - seems to mark the height of oppression.

(Christman, 2020)

Since a thorough analysis of the notion of autonomy lies beyond the scope of this paper, for the sake of our argument we shall employ Gerald Dworkin's view that

autonomy is conceived of as a second-order capacity of persons to reflect critically upon their first-order preferences, desires, wishes, and so forth and the capacity to accept or attempt to change these in light of higherorder preferences and values. By exercising such a capacity, persons define their nature, give meaning and coherence to their lives, and take responsibility for the kind of person they are.

(Dworkin, 1988, p. 20)

Dworkin also espouses this concept in bioethics and medical ethics (Dworkin, 1988, pp. 80-120), where the notion of autonomy is generally associated with an informed and competent decision free from any external or internal manipulation or influence (Mackenzie, 2015, p. 278). Thus-conceived autonomy has its legal facet: informed consent. As Neil C. Manson and Onora O'Neill argue, there are two models of informed consent: "a disclosure-based account of informed consent" and "a transactional model of informed consent” (Manson, O’Neill, 2007, p. 69). The former emphasizes the disclosure of information as the key factor in the patient's 
decision on any medical interventions, and the latter involves an agency model of communication and stresses "communicative transactions" between agents engaged in requesting and giving informed consent. While in some medical procedures the disclosure-based form may be adequate, the applications of DBS and BCIs call for a different model. Since, in our view, the role of informed consent is essential in the debate on autonomy and DBS/ BCI, a more robust form of informed consent should be advocated in this case, Instead of relying on a narrow concept of autonomy in which almost all decisions must be free and voluntary, such a consent should be based on a less rigid and broader (and thus feasible) notion of autonomy, as well as on other fundamental factors, such as communication (taking patients' expectations and preferences into account) and well-being. We shall discuss this in more detail below.

\section{Neural Technologies: A Threat to Personal Autonomy?}

Arguably, deep brain stimulation and brain-computer interface devices, especially those based on closed-loop systems, raise ethical concerns about the risks of reducing a person's autonomy and keeping her/him outside the so-called decision loop. As described above, unlike open-loop systems (which only warn the patients and allow them to respond as they wish after being informed), closed-loop implantable devices for monitoring neural activity are activated automatically, and operate beyond a person's will. Simply put, a therapeutic action is undertaken solely by technology, based on the detection of neural activity. The introduction of DBS and BCIs in treatments of epilepsy, paralysis, and neurological and psychiatric symptoms and disorders has already triggered a wide-ranging debate on an array of issues, including autonomy, agency, and identity (Baylis, 2013; Fenton, Alpert, 2008; Friedrich, Racine, Steinert, Pömsl, Jox, 2021; Glannon, 2016; Goering, Klein, Dougherty, Widge, 2017; Klein et al., 2016; Schechtman, 2009, 2010), affective states (Steinert, Friedrich, 2020), neuroprivacy/mental privacy and mental integrity (Fontanillo Lopez, Li, Zhang, 2020; Lavazza, 2018; Schermer, 2009; Steinert, Friedrich, 2020), liability and possible malfunctions of the devices, data-protection, and neurohacking (Ienca, Haselager, 2016; Pugh et al., 2018; Yuste et al., 2017). 
While the possible impact of DBS and BCIs on personal identity has attracted ample scholarly attention, the autonomy-problem tends to be framed sketchily, even though almost all discussion-papers on the application of neural implants explicitly voice anxiety over their hazard to personal autonomy and authenticity. In view of a rapid advancement and increasing investments in this field of neurotechnology, the common belief (shared by both philosophers and the public opinion) that autonomy is a precious value calls for more attention to and a firmer conceptual grasp of the autonomyproblem in the context of DBS- and BCI-based therapies. In the section below, we review the frequently expressed ethical concerns about and arguments for DBS/BCIs being a threat to a person's autonomy. Importantly, this paper does not seek to present an account of autonomy, but to assess whether novel neural technologies indeed pose a serious threat to autonomy and to provide insight into a broader understanding of autonomy where autonomy is not necessarily jeopardized by the application of neural technologies.

\section{Being Outside the Decision Loop and Autonomy}

It has been generally assumed that if one cannot control one's activity, one is deprived of autonomy, while one's internal acceptance of and consent to the act about to happen are crucial in assessing one's autonomy. Consequently, the bioethical literature often cautions that the use of neural devices diminishes a person's autonomy. Exercising control over one's actions is often considered a sine qua non of being a free agent. McCann insists that "[i]t simply is not possible from my perspective as a decision maker that I should feel that I lack voluntary control of my decisions, because from my perspective they are the essence of voluntary control" (McCann, 2012, p. 254; see also Ginet, 1990; McCann, 1998). Yet the restrictive demand that for a person to be a free, autonomous agent every act should be voluntary and self-controlled is difficult, or even impossible, to meet. "Freedom comes in degrees," as Timothy O'Connor states (O'Connor, 2009, p. 119). Not all the choices we make in everyday life are properly voluntary in the sense of being preceded by internal acceptance; for instance, we obviously often do things out of habit, almost automatically, or based on our prior decision resulting from reflection and second-order volition. All habitual actions, such as tying shoes, playing the piano, or riding a bike, can serve as 
hackneyed examples of learned, rigid, automatic, and unreflective behavior (see, for example, Clarke, 2003, p. 122). Consequently, they fail to meet the generally acknowledged definitional criterion of a free or voluntary act. Nonetheless, the fact that they stem from a free choice is a sufficient guarantee of an agent's freedom. In an activity that unfolds as a series of actions, this definitional criterion remains unchallenged and is met if the initial decision, which commences the chain of actions, is made freely and voluntarily. Thus, Randolph Clarke and Robert Kane may be right to claim that overt habitual, automatic, or spontaneous actions can indeed be regarded as free because they result from "directly free choices" (Clarke, 2003; Kane, 1998). Therefore, although all of us tie shoes every day, it does not make us nonvoluntary, controlled, and deprived of freedom or autonomy.

Analogically, one does not lose self-sovereignty and autonomy by simply not being in total and constant control of administering medications and thus falling outside the decision loop. Control and the freedom of decisionmaking are often recognized as two main components of being autonomous. Yet, being in control may fluctuate between being in full control and acting automatically, even within one day, depending on the action in which we are engaged at a given moment. Being free in making decisions is also gradable and hinges on various factors. If this is the case, autonomy, too, should be thought of as gradable, within the framework of O'Connor theory.

A look at particular syndromes will help us assess the impact that DBS and BCIs may have on autonomy. Given that the use of closed-loop systems in the treatment of drug-resistant epilepsy has been well documented (Sisterson, Wozny, Kokkinos, Constantino, Richardson, 2019) and addressed in the context of autonomy (Gilbert, O'Brian, Cook, 2018), it is a suitable starting point for our analysis. Importantly, the treatment of drug-resistant epilepsy is one of the most convincing and successful medical applications of closed-loop systems. For example, Gregory K. Bergey, Martha J. Morrell, Eli M. Mizrahi, et al. (Bergey et al., 2015) have assessed the long-term efficacy of responsive direct neurostimulation (the first responsive closed-loop focal cortical stimulator) in a group of people with epilepsy over $19.6( \pm 11.4)$ years. In the randomized blinded controlled trial, they found a statistically significant reduction in the frequency of tonic-clonic seizures and a significant increase in the quality of life during a mean follow-up of 5.4 years. 
Epilepsy is well known to considerably reduce the range of choices individuals may make and activities they may undertake. Paradoxical though it may sound, relieving epilepsy patients of the necessity to make decisions about behavior in expectation of seizures enables them to interact with their environment with more independence and freedom. Preventing epileptic episodes in fact widens the scope of options and makes possibilities real, resulting in a broader array of choices (Guerreiro, 2016). Riding a bicycle can serve as an example: being in the decisional loop entails deciding what to do (stop, get off the bike, lie down, etc., to take a medication) and interferes with the very activity of riding a bike and triggers a constraining pause in it. At the same time, being kept outside the decisional loop eliminates the constraint, interruption, and the necessity to counteract an unwanted neural episode. What is more, research shows that frequent and unpredictable epileptic episodes may contribute to a significant deterioration of the quality of life (as a result of epileptic episodes themselves, comorbid cognitive or affective disorders, and side effects of pharmacological treatment) (Baranowski, 2018; Tedrus, Crepaldi, de Almeida Fischer, 2020), in extreme cases leading to a gradual withdrawal from social life, such as entertainment, sports, or traveling. Brain-computer interfaces and deep brain stimulation devices may not only reduce symptoms and help treat syndromes (Klinger, Mittal, 2018; Lee, Lozano, Dallapiazza, Lozano, 2019; Rosenfeld, Wong, 2017; Salanova, 2018), but also lessen the fear of symptoms of diseases. Thus, keeping an agent outside the decisional loop enhances her/his sense of agency and of being the author of her/his own life-biography.

Habitual acts of obsessive-compulsive character are another case relevant to our argument. Recent studies have found that deep brain stimulation devices may have a significant positive effect on mental processes of people with severe, resistant, and chronic obsessive-compulsive disorders (Rapinesi et al., 2019), with the prospects being particularly promising for closed-loop devices (Tastevin, Spatola, Régis, Lançon, Richieri, 2019). Bothersome and intrusive thoughts that increase frustration and compulsive behavior limit the sense of free decision-making (Cillo et al., 2019), and in some cases trigger the feeling of being burdened with what are perceived as excessive and external compulsion and influence. The symptoms reported by patients, such as a persistent urge to check whether water taps are closed or the light is off, an obsessive need to keep things in perfect order and symmetry, an obsessive fear of dirt, or intrusive and irresistible (often vulgar or obscene) 
thoughts that are contrary to a person's worldview, can breed helplessness in everyday life. Obsessive-compulsive disorders may undermine the sense of being the author of one's actions, which individuals identify as integral to their selves. The implementation of the neurostimulation system results in a complete disappearance or satisfactory control of the symptoms (Mosley et al., 2021), and may thus restore the sense of freedom of decisionmaking informed by one's preferences. In this way, DBS contributes to the strengthening of people's sense of agency, control, and personal autonomy. Patients' active involvement in controlling the device on a permanent basis (by means of an open loop, for example, via light or sound alarms) (Kellmeyer et al., 2016) may catalyze the exacerbation of symptoms and the intensification of obsessions and compulsions. Arguably, by operating beyond the person's control, the device enhances the positive effects of therapeutic intervention. Being out of the decision loop liberates patients from an excessive obsession loop and enables them to better control obsessive thoughts and behavior.

Persistent bothersome symptoms of mental or somatic disorders in some patients have been documented to result in a significant deterioration of their functioning in private, social, and professional life, weakening their ability and willingness to accomplish plans, goals, and aspirations (Dziwota, Stepulak, Włoszczak-Szubzda, Olajossy, 2018; Kupferberg, Bicks, Hasler, 2016; Perepezko et al., 2019). Brain-computer interfaces and closed-loop neurostimulators have been observed to help alleviate the symptoms and their consequences for the functioning of individuals with various neurological and psychiatric diseases at the stage of preclinical studies, clinical trials, and sometimes even in standard practice (Goering et al., 2017; Saha et al., 2021). Depressive disorders and locked-in syndrome are discussed below as examples of such diseases.

As studies have shown (Alexopoulos, 2005; Malhi, Mann, 2018), patients suffering from depressive disorders, who experience chronic sadness, anergy, and the lack of satisfaction from daily activities, report a considerable decrease in the quality of life, which may make them neglect basic life activities to the point of stopping eating and drinking in some extreme cases. Administered as last-line treatments, neurostimulation-based therapies are likely to eliminate treatment-resistant depressive syndromes, and thus to restore or even widen the range of choices and possibilities for a person to flourish (Dandekar, Fenoy, Carvalho, Soares, Quevedo, 2018). 
Prospects for the positive impact of neural technologies on the competencies of individuals have also been confirmed in the treatment of LIS patients, who have lost the ability to move and speak and are permanently paralyzed, as a result of an injury, infection, or progressive neurodegeneration, but retain full awareness (Abbasi, 2019; Capogrosso et al., 2016; Maiser, Kabir, Sabsevitz, Peltier, 2016). Though paralyzed, a group of patients with locked-in syndrome may display residual communication skills based on eyeball and eyelid movements (Laureys et al., 2005; Smith, Delargy, 2005). This severe neurological condition is characterized by tetraplegia and anarthria (bilateral paralysis of laryngeal and pharyngeal muscles), which preclude articulate speech, hinder the swallowing of food, impair facial expression, and cause pneumonia, pulmonary embolus or the aspiration of saliva, and even death (Smith, Delargy, 2005; Young, 2014). The ten-year survival rate in this syndrome is estimated at $80 \%$ (Smith, Delargy, 2005). Crucially, the deterioration of the patients' quality of life is severe. The symptoms and their consequences - inability to move and communicate, the sense of physical and psychological dependence on family and medical staff, etc. - often result in a prolonged mental crisis, depressive episodes, and even suicidal thoughts and tendencies. People with locked-in syndrome explain that the limited ability to communicate with the environment, which marginalizes them in the network of interactions, is among the worst emotional strains of their condition, surpassing even the inability to move (Fenton, Alpert, 2008). By expanding the communication skills of people with locked-in syndrome, BCI systems boost their contacts and augment the available forms of dialogue with family, relatives, and the medical staff (Milekovic et al., 2018). As Andrew Fenton and Sheri Alpert explain:

BCIs offer hope to at least some of those with LIS that they will be able to initiate and maintain communication, control television viewing, interact with others in cyberspace, manipulate objects in their environment using robotic arms or even control their movement in wheelchairs.

(Fenton, Alpert, 2008, p. 122)

As argued above, some mental and somatic diseases in fact significantly reduce personal autonomy, whereas the application of BCIs and DBS prevents or reduces the symptoms and widens the range of possibilities and options. The automatic systems of DBS and BCIs support people's cognitive abilities and halt the progression of disorders, which is correlated with the 
optimization of affective and volitional capacities, or the ability to speak and/or move. In this way, these technologies enhance a person's autonomy, even if (s)he is outside the decision loop.

\section{Informed Consent, Autonomy, and Well-Being}

Given that not each and every act is fully (or ideally) autonomous, that some acts result from previous deliberated higher-level decision-making processes, and that autonomy comes in degrees depending on various factors and circumstances, being outside the decisional loop - that is, having no control of the therapeutic device - is not synonymous with an autonomy deficit. It is informed consent that is the key factor in the decision process and the debate on personal autonomy in such cases. Thus, the person's decision to have a device operating beyond her/his control implanted is a major concern. If the decision is based on disclosed information about possible negative effects and the nature of the device, if it expresses the person's preferences and desires preceded by higher-level deliberation revealing a voluntary and free (autonomous) choice, and if it is entrenched in the person's life-plan, to claim that the device poses a threat to the person's autonomy is unfounded or, at least, poorly tenable. We argue that the decision (informed consent) to have the device is crucial in the evaluation of the person's autonomy. While every single activation of the device is indeed beyond the person's control, a voluntary and free consent is given beforehand to its subsequent activations, and, consequently, no act of activation is involuntary properly speaking. However, the model of informed consent that is mostly based on the disclosure of information and consent-requesting/giving does not suffice. A more robust understanding of informed consent is needed when administering treatments which involve neural technologies. In our view, two major aspects should be considered in remodeling the concept of informed consent. Firstly, factors such as communication and commitment between agents and trust between human agents (patient and physician) and also between human and non-human agents (patient and device) should be seriously taken into account. Also, in recasting the model of informed consent, the role of automatically initiated interventions of the device which stem from patients' autonomous decisions should be reinterpreted, possibly to 
acknowledge that autonomy is shared in this context. As Sara Goering, Eran Klein, Darin D. Dougherty, and Alik S. Widge put it:

Rejecting the label of brain manipulation does not obviate the underlying concern about agency, but it may leave open a door to another way to address this. If we take a more neutral stance on neural devices, we see that it is possible - and maybe advantageous - to extend a relational account of agency to include devices themselves.

(Goering et al., 2017, p. 67).

An autonomous decision in which one consents to share one's decision-making with neural devices (just like we share the decision-making process with our partners, for example) and be treated by them remains autonomous. The application of neural technologies is not an all-or-nothing scenario for respecting or violating personal autonomy.

Secondly, a person's well-being should be recognized as one of the essential factors in a new model of informed consent concerning the application of neural technologies. By well-being we understand a philosophical notion of well-being that goes beyond its medical use and is not limited to (though it may be combined with) the quality of life, but primarily means what is good for you. If we construe "what is good for you" as something that you desire, or even as something that you should desire, something that should be a prudential value (Crisp, 2017), the use of DBS and BCIs undoubtedly contributes to the well-being of some persons (while meeting the condition of "doing no harm to others"). It not only expands the range of lifepossibilities, choices, and acts, enabling people to act as they wish and to make the options realizable, but also empowers them to shape their lives according to their preferences and to fulfill their desires, enabling them to be what they desire to be. Even if our approach of adopting a subjective stance on well-being is susceptible to criticism, the way any other desirebased theory is, it may redirect the debate on the use of DBS and BCIs to foreground other values than autonomy. After all, some philosophers teach us that the well-being of others (just like our own well-being) should be our concern (Lazari-Radek, 2021). 


\section{Some Limitations to Our Study}

The analytical approach we adopt in our study on the concerns about the threats that DBS and BCIs pose to autonomy and free decision-making has its limitations. While we believe that most arguments advanced in the debate implicitly presuppose a notion of autonomy that is demanding and difficult (if not impossible) to attain, more research on the attitudes of individuals who use the neural technologies is urgently needed to evaluate their longterm use, risks, and benefits. Also, the dynamic development of the systems, as a result of which their potential risks and therapeutical benefits change rapidly, contributes to difficulties in providing an all-or-nothing assessment of the impact of technology on autonomy and well-being.

Little empirical data is now available on the patients' sense of autonomy or the negative effects of using the technologies, and most studies on the use of DBS and BCIs offer inconclusive findings that

1) Being in the loop may partly increase a sense of autonomy over decisionmaking. 2) Being in the loop may partly decrease a sense of autonomy over decisionmaking. 3) Being in the loop may not impact a sense of autonomy over decisionmaking.

(Gilbert et al., 2018, p. 3201)

There is, however, some research on using closed-loop systems by diabetes patients which shows that, after a three-month clinical trial of a closedloop device automatically delivering insulin, they positively evaluated its medical and non-medical benefits, explicitly expressed their trust and confidence in the device, and reported the feeling of being more independent, free, flexible, and active in life (Lawton et al., 2019). Not only are these findings important in purely medical terms, but they also empirically confirm that being out of the loop may enhance the sense of control.

\section{Conclusion}

The alleged risk of autonomy loss is an extension of commonly expressed fears of losing control, freedom, and the true self, which recur in discussions

1 See also Burwell et al., 2017; Gilbert, 2015; Lahr et al., 2015. 
on freedom and determinism. Some believe that "if determinism is true, then we are like puppets on strings," as Clarke rightly summarizes the fears voiced in the debate to claim that "[w] e make decisions and act even if determinism is true; we are thus unlike puppets" (Clarke, 2003, p. 8). Being controlled by a machine seems to be the worst-case scenario to be avoided at all cost. However, if we adopt a broader and less demanding notion of autonomy which does not require that all decisions should be absolutely free, the initial deliberative element in the decisions-making process combined with acting in accordance with one's preference and desires is enough to ensure freedom, voluntariness, and personal autonomy. Consequently, neural technologies can be considered just another element of an interplay enabling and securing the realization of previously expressed preferences.

Social interactions, the capacity to communicate with others, and the chance to flourish and to fulfill one's desires are important factors in what makes life a good one and, consequently, in a person's well-being. Being deprived of them spawns ill-being. Systems based on brain-computer interfaces and neurostimulators enhance and augment communicational, emotional, and volitional competencies, promoting the active redefining, negotiating, shaping, and modifying of an individual's positions in a relational network based on subjective beliefs about what is good for her/him. Such systems not only help people overcome burdensome symptoms and strengthen cognitive, affective, and behavioral abilities, but also mediate the realization of the internalized ideas, perspectives, desires, and interests of a relational agent to foster her/his well-being.

The concerns voiced in the debate on neural technologies to a certain extant mirror anxieties rife in disputes over human enhancement and transhumanism. The opponents of human enhancement portray it as procedures and processes that imperil our humanity and will ultimately and inevitably make us lose our human nature and become "something else." Neural technologies tend to be perceived as bringing doom upon humanity. We are convinced, however, that it does not mean that the future that is to come (even if it will indeed involve the doom of humans) will bring nothing but despair and misery. Another scenario is possible as well. In this scenario, humans will step aside to make room for "something else." Whether this "something else" will be something more or something less lies in our hands and is our moral duty to determine. There is a possible future in which we become posthumans or, as Aleksandra Łukaszewicz Alcaraz phrases it, cyborg persons (Łukaszewicz 
Alcaraz, 2021), a future in which the opposition of machine and organism is replaced by machinic-organic coexistence, paving the way for new definitions of persons and new kinds of persons. The way we understand, use, and coexist with new technologies is still open and "involves learning about and making use of new technologies that can increase our capacities and life expectancy, questioning common assumptions, and transforming ourselves ready for the future, rising above outmoded human beliefs and behaviors" (More, 2021).

\section{Bibliography}

Abbasi, J. (2019). Advanced Brain-Computer Interface for People With Paralysis. Journal of the American Medical Association, 321 (6), 537. DOI: 10.1001/ jama.2019.0294.

Alexopoulos, G.S. (2005). Depression in the Elderly. Lancet, 365 (9475), 1961-1970. DOI: 10.1016/S0140-6736(05)66665-2.

Arya, S., Filkowski, M.M., Nanda, P., Sheth, S.A. (2019). Deep Brain Stimulation for Obsessive-Compulsive Disorder. Bulletin of the Menninger Clinic, 83 (1), 84-96. DOI: 10.1521/bumc.2019.83.1.84.

Aum, D.J., Tierney, T.S. (2018). Deep Brain Stimulation: Foundations and Future Trends. Frontiers in Bioscience, 23, 162-182. DOI: 10.2741/4586.

Baranowski, C.J. (2018). The Quality of Life of Older Adults with Epilepsy: A Systematic Review. Seizure, 60, 190-197. DOI: 10.1016/j.seizure.2018.06.002.

Batista, A. (2020). Brain-Computer Interfaces for Basic Neuroscience. Handbook of Clinical Neurology, 168, 233-247. DOI: 10.1016/b978-0-444-639349.00017-2.

Baylis, F. (2013). "I Am Who I Am": On the Perceived Threats to Personal Identity from Deep Brain Stimulation. Neuroethics, 6 (3), 513-526. DOI: 10.1007/ s12152-011-9137-1.

Belkacem, A.N., Jamil, N., Palmer, J.A., Ouhbi, S., Chen, C. (2020). Brain Computer Interfaces for Improving the Quality of Life of Older Adults and Elderly Patients. Frontiers in Neuroscience, 14, 692. DOI: 10.3389/fnins.2020.00692.

Bergey, G.K., Morrell, M.J., Mizrahi, E.M., Goldman, A., King-Stephens, D., Nair, D., Srinivasan, S., Jobst, B., Gross, R.E., Shields, D.C., Barkley, G., Salanova, V., Olejniczak, P., Cole, A., Cash, S.S., Noe, K., Wharen, R., Worrell, G., Murro, A.M., Edwards, J., Duchowny, M., Spencer, D., Smith, M., Geller, E., Gwinn, R., Skidmore, C., Eisenschenk, S., Berg, M., Heck, C., 
Van Ness, P., Fountain, N., Rutecki, P., Massey, A., O’Donovan, C., Labar, D., Duckrow, R.B., Hirsch, L.J., Courtney, T., Sun, F.T., Seale, C.G. (2015). Long-Term Treatment with Responsive Brain Stimulation in Adults with Refractory Partial Seizures. Neurology, 84 (8), 810-817. DOI: 10.1212/ WNL.0000000000001280.

Burwell, S., Sample, M., Racine, E. (2017). Ethical Aspects of Brain Computer Interfaces: A Scoping Review. BMC Medical Ethics, 18 (1), 60. DOI: 10.1186/ s12910-017-0220-y.

Capogrosso, M., Milekovic, T., Borton, D., Wagner, F., Moraud, E.M., Mignardot, J.B., Buse, N., Gandar, J., Barraud, Q., Xing, D., Rey, E., Duis, S., Jianzhong, Y., Ko, W.K., Li, Q., Detemple, P., Denison, T., Micera, S., Bezard, E., Bloch, J., Courtine G. (2016). A Brain-Spine Interface Alleviating Gait Deficits after Spinal Cord Injury in Primates. Nature, 539 (7628), 284-288. DOI: 10.1038/ nature20118.

Christman, J. (2020). Autonomy in Moral and Political Philosophy. In: E.N. Zalta (ed.), The Stanford Encyclopedia of Philosophy. Retrieved from: https://plato. stanford.edu/archives/fall2020/entries/autonomy-moral (31.05.2021).

Cillo, A., Bonetti, M., Burro, G., Di Serio, C., De Filippis, R., Martoni, R.M. (2019). Neurocognitive Assessment in Obsessive Compulsive Disorder Patients: Adherence to Behavioral Decision Models. PloS One, 14 (2), e0211856. DOI: 10.1371/journal.pone.0211856.

Clarke, R. (2003). Libertarian Accounts of Free Will. Oxford: Oxford University Press.

Crisp, R. (2017). Well-Being. In: E.N. Zalta (ed.), The Stanford Encyclopedia of Philosophy. Retrieved from: https://plato.stanford.edu/archives/fall2017/entries/ well-being (6.05.2021).

Dalton, B., Bartholdy, S., Campbell, I.C., Schmidt, U. (2018). Neurostimulation in Clinical and Sub-clinical Eating Disorders: A Systematic Update of the Literature. Current Neuropharmacology, 16 (8), 1174-1192. DOI: 10.2174/ $1570159 X 16666180108111532$.

Dandekar, M.P., Fenoy, A.J., Carvalho, A.F., Soares, J.C., Quevedo, J. (2018). Deep Brain Stimulation for Treatment-Resistant Depression: An Integrative Review of Preclinical and Clinical Findings and Translational Implications. Molecular Psychiatry, 23 (5), 1094-1112. DOI: 10.1038/mp.2018.2.

Davidoff, E.J. (2020). Agency and Accountability: Ethical Considerations for BrainComputer Interfaces. The Rutgers Journal of Bioethics, 11, 9-20. 
Dougherty, D.D. (2018). Deep Brain Stimulation: Clinical Applications. The Psychiatric Clinics of North America, 41 (3), 385-394. DOI: 10.1016/j.psc.2018.04.004.

Drobisz, D., Damborská, A. (2019). Deep Brain Stimulation Targets for Treating Depression. Behavioural Brain Research, 359, 266-273. DOI: 10.1016/j. bbr.2018.11.004.

Dworkin, G. (1988). The Theory and Practice of Autonomy (Cambridge Studies in Philosophy). Cambridge: Cambridge University Press.

Dziwota, E., Stepulak, M.Z., Włoszczak-Szubzda, A., Olajossy, M. (2018). Social Functioning and the Quality of Life of Patients Diagnosed with Schizophrenia. Annals of Agricultural and Environmental Medicine, 25 (1), 50-55. DOI: $10.5604 / 12321966.1233566$.

Edwards, C.A., Kouzani, A., Lee, K.H., Ross, E.K. (2017). Neurostimulation Devices for the Treatment of Neurologic Disorders. Mayo Clinic Proceedings, 92 (9), 1427-1444. DOI: 10.1016/j.mayocp.2017.05.005.

Feinberg, J. (1980). Rights, Justice, and the Bounds of Liberty: Essays in Social Philosophy. Princeton, NJ: Princeton University Press.

Fenton, A., Alpert, S. (2008). Extending Our View on Using BCIs for Locked-in Syndrome. Neuroethics, 1 (2), 119-132. DOI: 10.1007/s12152-008-9014-8.

Fontanillo Lopez, C.A., Li, G., Zhang, D. (2020). Beyond Technologies of Electroencephalography-Based Brain-Computer Interfaces: A Systematic Review From Commercial and Ethical Aspects. Frontiers in Neuroscience, 14, 611130. DOI: $10.3389 /$ fnins.2020.611130.

Friedrich, O., Racine, E., Steinert, S., Pömsl, J., Jox, R.J. (2021). An Analysis of the Impact of Brain-Computer Interfaces on Autonomy. Neuroethics, 14, 17-29. DOI: $10.1007 / \mathrm{s} 12152-018-9364-9$.

Ghasemi, P., Sahraee, T., Mohammadi, A. (2018). Closed- and Open-loop Deep Brain Stimulation: Methods, Challenges, Current and Future Aspects. Journal of Biomedical Physics and Engineering, 8 (2), 209-216. DOI: 10.31661/ jbpe.v8i2.898.

Gilbert, F. (2015). A Threat to Autonomy? The Intrusion of Predictive Brain Implants. AJOB Neuroscience, 6 (4), 4-11. DOI: 10.1080/21507740.2015.1076087.

Gilbert, F., O’Brient, T., Cook, M. (2018). The Effects of Closed-Loop Brain Implants on Autonomy and Deliberation: What are the Risks of Being Kept in the Loop? Cambridge Quarterly of Healthcare Ethics, 27 (2), 316-325. DOI:10.1017/ S0963180117000640. 
Gilbert, F., Cook, M., O’Brien, T., Illes, J. (2019). Embodiment and Estrangement: Results from a First-in-Human "Intelligent BCI" Trial. Science and Engineering Ethics, 25 (1), 83-96. DOI: 10.1007/s11948-017-0001-5.

Ginet, C. (1990). On Action. Cambridge: Cambridge University Press.

Glannon, W. (2016). Ethical Issues in Neuroprosthetics. Journal of Neural Engineering, 13 (2), 021002. DOI: 10.1088/1741-2560/13/2/021002.

Goering, S., Klein, E., Dougherty, D.D., Widge, A.S. (2017). Staying in the Loop: Relational Agency and Identity in Next-Generation DBS for Psychiatry. $A J O B$ Neuroscience, 8 (2), 59-70. DOI: 10.1080/21507740.2017.1320320.

Guerreiro, C.M. (2016). Epilepsy: Is there Hope? Indian Journal of Medical Research, 144 (5), 657-660. DOI: 10.4103/ijmr.IJMR_1051_16.

Habets, J., Heijmans, M., Kuijf, M.L., Janssen, M., Temel, Y., Kubben, P.L. (2018). An Update on Adaptive Deep Brain Stimulation in Parkinson's Disease. Movement Disorders: Official Journal of the Movement Disorder Society, 33 (12), 1834-1843. DOI: $10.1002 / \mathrm{mds} .115$.

Ienca, M., Haselager, P. (2016). Hacking the Brain: Brain-Computer Interfacing Technology and the Ethics of Neurosecurity. Ethics and Information Technology, 18 (2), 117-129. DOI: 10.1007/s10676-016-9398-9.

Iwry, J., Yaden, D.B., Newberg, A.B. (2017). Noninvasive Brain Stimulation and Personal Identity: Ethical Considerations. Frontiers in Human Neuroscience, 11, 281. DOI: 10.3389/fnhum.2017.00281.

Jianhong, W., Ramirez-Mendoza, R.A. (2020). The Practical Analysis for Closed-Loop System Identification. Cogent Engineering, 7 (1). DOI: 10.1080/23311916.2020.1796895.

Kane, R. (1998). The Significance of Free Will. Oxford: Oxford University Press.

Kawala-Sterniuk, A., Browarska, N., Al-Bakri, A., Pelc, M., Zygarlicki, J., Sidikova, M., Martinek, R., Gorzelanczyk, E.J. (2021). Summary of over Fifty Years with Brain-Computer Interfaces - A Review. Brain Sciences, 11 (1), 43. DOI: 10.3390/brainsci11010043.

Kellmeyer, P., Cochrane, T., Müller, O., Mitchell, C., Ball, T., Fins, J.J., BillerAndorno, N. (2016). The Effects of Closed-Loop Medical Devices on the Autonomy and Accountability of Persons and Systems. Cambridge Quarterly of Healthcare Ethics: CQ: The International Journal of Healthcare Ethics Committees, 25 (4), 623-633. DOI: 10.1017/S0963180116000359.

Kellmeyer, P., Grosse-Wentrup, M., Schulze-Bonhage, A., Ziemann, U., Ball, T. (2018). Electrophysiological Correlates of Neurodegeneration in Motor and 
Non-Motor Brain Regions in Amyotrophic Lateral Sclerosis-Implications for Brain-Computer Interfacing. Journal of Neural Engineering, 15 (4), 041003. DOI: 10.1088/1741-2552/aabfa5.

Klein, E. (2020). Ethics and the Emergence of Brain-Computer Interface Medicine. Handbook of Clinical Neurology, 168, 329-339. DOI: 10.1016/B978-0-44463934-9.00024-X.

Klein, E., Goering, S., Gagne, J., Shea, C.V., Franklin, R., Zorowitz, S., Dougherty, D.D., Widge, A.S. (2016). Brain-Computer Interface-Based Control of ClosedLoop Brain Stimulation: Attitudes and Ethical Considerations. Brain-Computer Interfaces, 3 (3), 140-148. DOI: 10.1080/2326263X.2016.1207497.

Klinger, N., Mittal, S. (2018). Deep Brain Stimulation for Seizure Control in DrugResistant Epilepsy. Neurosurgical Focus, 45 (2), E4. DOI: 10.3171/2018.4.FOCUS1872.

Kogan, M., McGuire, M., Riley, J. (2019). Deep Brain Stimulation for Parkinson Disease. Neurosurgery Clinics of North America, 30 (2), 137-146. DOI: 10.1016/j.nec.2019.01.001.

Kupferberg, A., Bicks, L., Hasler, G. (2016). Social Functioning in Major Depressive Disorder. Neuroscience and Biobehavioral Reviews, 69, 313-332. DOI: 10.1016/j.neubiorev.2016.07.002.

Lahr, J., Schwartz, C., Heimbach, B., Aertsen, A., Rickert, J., Ball, T. (2015). Invasive Brain-Machine Interfaces: A Survey of Paralyzed Patients' Attitudes, Knowledge and Methods of Information Retrieval. Journal of Neural Engineering, 12 (4), 043001. DOI: 10.1088/1741-2560/12/4/043001.

Lake, W., Hedera, P., Konrad, P. (2019). Deep Brain Stimulation for Treatment of Tremor. Neurosurgery Clinics of North America, 30 (2), 147-159. DOI: 10.1016/j.nec.2019.01.002.

Laureys, S., Pellas, F., Van Eeckhout, P., Ghorbel, S., Schnakers, C., Perrin, F., Berré, J., Faymonville, M.E., Pantke, K.H., Damas, F., Lamy, M., Moonen, G., Goldman, S. (2005). The Locked-in Syndrome: What is It Like to be Conscious but Paralyzed and Voiceless? Progress in Brain Research, 150, 495-511. DOI: 10.1016/S0079-6123(05)50034-7.

Lavazza, A. (2018). Freedom of Thought and Mental Integrity: The Moral Requirements for Any Neural Prosthesis. Frontiers in Neuroscience, 12, 82. DOI: 10.3389/fnins.2018.00082.

Lawton, J., Blackburn, M., Rankin, D., Allen, J.M., Campbell, F.M., Leelarathna, L., Tauschmann, M., Thabit, H., Wilinska, M.E., Elleri, D., Hovorka, R. (2019). Participants' Experiences of, and Views About, Daytime 
Use of a Day-and-Night Hybrid Closed-Loop System in Real Life Settings: Longitudinal Qualitative Study. Diabetes Technology \& Therapeutics, 21 (3), 119-127. DOI: 10.1089/dia.2018.0306.

Lazari-Radek, de, K. (2021). Godny pożądania stan świadomości. O przyjemności jako wartości ostatecznej. Łódź: Wydawnictwo Uniwersytetu Łódzkiego.

Lee, D.J., Lozano, C.S., Dallapiazza, R.F., Lozano, A.M. (2019). Current and Future Directions of Deep Brain Stimulation for Neurological and Psychiatric Disorders. Journal of Neurosurgery, 131 (2), 333-342. DOI: 10.3171/2019.4.JNS181761.

Leeb, R., Pérez-Marcos, D. (2020). Brain-Computer Interfaces and Virtual Reality for Neurorehabilitation. Handbook of Clinical Neurology, 168, 183-197. DOI: 10.1016/B978-0-444-63934-9.00014-7.

Lipsman, N., Woodside, D.B., Giacobbe, P., Hamani, C., Carter, J.C., Norwood, S.J., Sutandar, K., Staab, R., Elias, G., Lyman, C.H., Smith, G.S., Lozano, A.M. (2013). Subcallosal Cingulate Deep Brain Stimulation for TreatmentRefractory Anorexia Nervosa: A Phase 1 Pilot Trial. Lancet, 381 (9875), 1361-1370. DOI: 10.1016/S0140-6736(12)62188-6.

Łukaszewicz Alcaraz, A. (2021). Are Cyborgs Persons? An Account of Futurist Ethics. Palgrave Macmillan.

Mackenzie, C., Stoljar, N. (eds.) (2000). Relational Autonomy: Feminist Perspectives on Autonomy, Agency, and the Social Self. Oxford: Oxford University Press.

Mackenzie, C. (2015). Autonomy. In: Arras, J.D., Fenton, E., Kukla R. (eds.), The Routledge Companion to Bioethics (pp. 277-290). New York: Routledge.

Maiser, S., Kabir, A., Sabsevitz, D., Peltier, W. (2016). Locked-In Syndrome \#303. Journal of Palliative Medicine, 19 (4), 460-461. DOI: 10.1089/jpm.2016.0016.

Malek, N. (2019). Deep Brain Stimulation in Parkinson's Disease. Neurology India, 67 (4), 968-978. DOI: 10.4103/0028-3886.266268.

Malhi, G.S., Mann, J.J. (2018). Depression. Lancet, 392 (10161), 2299-2312. DOI: 10.1016/S0140-6736(18)31948-2.

Manson, N., O'Neill, O. (2007). Rethinking Informed Consent in Bioethics. Cambridge: Cambridge University Press.

Marchetti, M., Priftis, K. (2015). Brain Computer Interfaces in Amyotrophic Lateral Sclerosis: A Metanalysis. Clinical Neurophysiology, 126 (6), 1255-1263. DOI: 10.1016/j.clinph.2014.09.017. 
Maynard, A.D., Scragg, M. (2019). The Ethical and Responsible Development and Application of Advanced Brain Machine Interfaces. Journal of Medical Internet Research, 21 (10), e16321. DOI: 10.2196/16321.

McCann, H.J. (1998). The Works of Agency: On Human Action, Will, and Freedom. Ithaca: Cornell University Press.

McCann, H.J. (2012). Making Decisions. Philosophical Issues, 22, 246-263. DOI: 10.1111/j.1533-6077.2012.00228.x.

McGie, S.C., Nagai, M.K., Artinian-Shaheen, T. (2013). Clinical Ethical Concerns in the Implantation of Brain-Machine Interfaces. IEEE pulse, 4 (2), 32-37. DOI: 10.1109/MPUL.2013.2242014.

Mele, A.R. (1995). Autonomous Agents: From Self-Control to Autonomy. Oxford: Oxford University Press.

Meyers, D. (1987). Personal Autonomy and the Paradox of Feminine Socialization. The Journal of Philosophy, 84 (11), 619-628.

Milekovic, T., Sarma, A.A., Bacher, D., Simeral, J.D., Saab, J., Pandarinath, C., Sorice, B.L., Blabe, C., Oakley, E.M., Tringale, K.R., Eskandar, E., Cash, S.S., Henderson, J.M., Shenoy, K.V., Donoghue, J.P., Hochberg, L.R. (2018). Stable Long-Term BCI-Enabled Communication in ALS and Locked-in Syndrome Using LFP Signals. Journal of Neurophysiology, 120 (1), 343-360. DOI: /10.1152/jn.00493.2017.

More, M. (1995). The Extropian Principles. Version 2.6. Retrieved from: https:// www.alamut.com/subj/ideologies/manifestos/extropian_principles.html (13.04.2021).

More, M. (2021). FAQ 3. Retrieved from: https://www.maxmore.com/ (12.04.2021).

Mosley, P.E., Windels, F., Morris, J., Coyne, T., Marsh, R., Giorni, A., Mohan, A., Sachdev P., O’Leary, E., Boschen, M., Sah, P., Silburn, P.A. (2021). A Randomised, Double-Blind, Sham-Controlled Trial of Deep Brain Stimulation of the Bed Nucleus of the Stria Terminalis for Treatment-Resistant Obsessive-Compulsive Disorder. Translational Psychiatry, 11 (1), 190. DOI: 10.1038/s41398-021-01307-9.

Neumann, W.J., Turner, R.S., Blankertz, B., Mitchell, T., Kühn, A.A., Richardson, R.M. (2019). Toward Electrophysiology-Based Intelligent Adaptive Deep Brain Stimulation for Movement Disorders. Neurotherapeutics, 16 (1), 105-118. DOI: 10.1007/s13311-018-00705-0.

Nozick, R. (1974). Anarchy, State, and Utopia. New York: Basic Books. 
O’Brolcháin, F., Jacquemard, T., Monaghan D., O’Connor N., Novitzky, P., Gordijn, B. (2016). The Convergence of Virtual Reality and Social Networks: Threats to Privacy and Autonomy. Science and Engineering Ethics, 22 (1), 1-29. DOI: 10.1007/s11948-014-9621-1.

O’Connor, T. (2009). Degrees of Freedom. Philosophical Explorations, 12 (2), 119-125. DOI: 10.1080/13869790902838472.

O’Neill, O. (2002). Autonomy and Trust in Bioethics. Cambridge: Cambridge University Press.

Perepezko, K., Hinkle, J.T., Shepard, M.D., Fischer, N., Broen, M.P.G., Leentjens, A.F.G., Gallo, J.J., Pontone, G.M. (2019). Social Sole Functioning in Parkinson's Disease: A Mixed-Methods Systematic Review. International Journal of Geriatric Psychiatry, 34 (8), 1128-1138. DOI: 10.1002/gps.5137.

Potter, S.M., El Hady, A., Fetz, E.E. (2014). Closed-Loop Neuroscience and Neuroengineering. Frontiers in Neural Circuits, 8, 115. DOI: 10.3389/fncir.2014.00115.

Pugh, J., Pycroft, L., Sandberg, A., Aziz, T., Savulescu, J. (2018). Brainjacking in Deep Brain Stimulation and Autonomy. Ethics and Information Technology, 20 (3), 219-232. DOI: 10.1007/s10676-018-9466-4.

Rachid, F. (2018). Neurostimulation Techniques in the Treatment of Cocaine Dependence: A Review of the Literature. Addictive Behaviors, 76, 145-155. DOI: 10.1016/j.addbeh.2017.08.004.

Rapinesi, C., Kotzalidis, G.D., Ferracuti, S., Sani, G., Girardi, P., Del Casale, A. (2019). Brain Stimulation in Obsessive-Compulsive Disorder (OCD): A Systematic Review. Current Neuropharmacology, 17 (8), 145-155. DOI: 10.217 4/1570159X117666190409142555.

Rodrigues, F.B., Duarte, G.S., Prescott, D., Ferreira, J., Costa, J. (2019). Deep Brain Stimulation for Dystonia. The Cochrane Database of Systematic Reviews, 1 (1), CD012405. DOI: 10.1002/14651858.CD012405.pub2.

Rosenfeld, J.V, Wong, Y.T. (2017). Neurobionics and the Brain-Computer Interface: Current Applications and Future Horizons. Medical Journal of Australia, 206 (8), 363-368. DOI: 10.5694/mja16.01011.

Saha, S., Mamun, K.A., Ahmed, K., Mostafa, R., Naik, G.R., Darvishi, S., Khandoker, A.H., Baumert, M. (2021). Progress in Brain Computer Interface: Challenges and Opportunities. Frontiers in Systems Neuroscience, 15, 578875. DOI: $10.3389 /$ fnsys.2021.578875.

Salanova, V. (2018). Deep Brain Stimulation for Epilepsy. Epilepsy \& Behavior, 88S, 21-24. DOI: 10.1016/j.yebeh.2018.06.041. 
Sandel, M. (2007). The Case against Perfection: Ethics in the Age of Genetic Engineering. Cambridge, MA-London: Harvard University Press.

Schechtman, M. (2009). Getting our Stories Straight: Self-Narrative and Personal Identity. In: Mathews D.J.H., Bok H., Rabins P.V. (eds.), Personal Identity and Fractured Selves: Perspectives from Philosophy, Ethics, and Neuroscience (pp. 65-92). Baltimore: Johns Hopkins University Press.

Schechtman, M. (2010). Philosophical Reflections on Narrative and Deep Brain Stimulation. The Journal of Clinical Ethics, 21 (2), 133-139.

Schermer, M. (2009). The Mind and the Machine. On the Conceptual and Moral Implications of Brain Machine Interaction. Nano Ethics, 3 (3), 217. DOI: 10.1007/s11569-009-0076-9.

Sisterson, N.D., Wozny, T.A., Kokkinos, V., Constantino, A., Richardson, R.M. (2019). Closed-Loop Brain Stimulation for Drug-Resistant Epilepsy: Towards an Evidence-Based Approach to Personalized Medicine. Neurotherapeutics, 16 (1), 119-127. DOI: 10.1007/s13311-018-00682-4.

Sisterson, N.D., Kokkinos, V. (2020). Neuromodulation of Epilepsy Networks. Neurosurgery Clinics of North America, 31 (3), 459-470. DOI: 10.1016/j.nec.2020.03.009.

Smith, E., Delargy, M. (2005). Locked-in Syndrome. BMJ, 330 (7488), 406-409. DOI: $10.1136 / \mathrm{bmj} .330 .7488 .406$.

Steigerwald, F., Matthies, C., Volkmann, J. (2019). Directional Deep Brain Stimulation. Neurotherapeutics, 16 (1), 100-104. DOI: 10.1007/s13311-018-0667-7.

Steinert, S., Friedrich, O. (2020). Wired Emotions: Ethical Issues of Affective BrainComputer Interfaces. Science and Engineering Ethics, 26 (1), 351-367. DOI: 10.1007/s11948-019-00087-2.

Sun, F.T., Morrell, M.J. (2014). Closed-Loop Neurostimulation: The Clinical Experience. Neurotherapeutics, 11 (3), 553-563. DOI: 10.1007/s13311-014-0280-3.

Tastevin, M., Spatola, G., Régis, J., Lançon, C., Richieri, R. (2019). Deep Brain Stimulation in the Treatment of Obsessive-Compulsive Disorder: Current Perspectives. Neuropsychiatric Disease and Treatment, 15, 1259-1272. DOI: 10.2147/NDT.S178207.

Tedrus, G., Crepaldi, C.R., de Almeida Fischer, B. (2020). Quality of Life Perception in Patients with Epilepsy for a Period of 4 Years. Epilepsy \& Behavior, 111, 107318. DOI: 10.1016/j.yebeh.2020.107318. 
Thinnes-Elker, F., Iljina, O., Apostolides, J.K., Kraemer, F., Schulze-Bonhage, A., Aertsen, A., Ball, T. (2012). Intention Concepts and Brain-Machine Interfacing. Frontiers in Psychology, 3, 455. DOI: 10.3389/fpsyg.2012.00455.

Vansteensel, M.J., Jarosiewicz, B. (2020). Brain-Computer Interfaces for Communication. Handbook of Clinical Neurology, 168, 67-85. DOI:10.1016/ B978-0-444-63934-9.00007-X.

Vassileva, A., van Blooijs, D., Leijten, F., Huiskamp, G. (2018). Neocortical Electrical Stimulation for Epilepsy: Closed-Loop versus Open-Loop. Epilepsy research, 141, 95-101. DOI: 10.1016/j.eplepsyres.2018.02.010.

Vaughan, T.M. (2020). Brain-Computer Interfaces for People with Amyotrophic Lateral Sclerosis. Handbook of Clinical Neurology, 168, 33-38. DOI: 10.1016/ B978-0-444-63934-9.00004-4.

White-Dzuro, G.A., Lake, W., Neimat, J.S. (2017). Subpectoral Implantation of Internal Pulse Generators for Deep Brain Stimulation: Technical Note for Improved Cosmetic Outcomes. Operative Neurosurgery, 13 (4), 529-534. DOI: 10.1093/ons/opx018.

Wolkenstein, A., Jox, R., Friedrich, O. (2018). Brain-Computer Interfaces: Lessons to Be Learned from the Ethics of Algorithms. Cambridge Quarterly of Healthcare Ethics, 27 (4), 635-646. DOI: 10.1017/S0963180118000130.

Xu, W., Zhang, C., Deeb, W., Patel, B., Wu, Y., Voon, V., Okun, M.S., Sun, B. (2020). Deep Brain Stimulation for Tourette's Syndrome. Translational Neurodegeneration, 9, 4. DOI: 10.1186/s40035-020-0183-7.

Yan, H., Toyota, E., Anderson, M., Abel, T.J., Donner, E., Kalia, S.K., Drake, J., Rutka, J.T., Ibrahim, G.M. (2018). A Systematic Review of Deep Brain Stimulation for the Treatment of Drug-Resistant Epilepsy in Childhood. Journal of Neurosurgery. Pediatrics, 23 (3), 274-284. DOI: 10.3171/2018.9.PEDS18417.

Young, G.B. (2014). Locked-In Syndrome. In: Daroff, R., Aminoff, M. (eds.), Encyclopedia of the Neurological Sciences (p. 916). Elsevier.

Yuste, R., Goering, S., Arcas, B., Bi, G., Carmena, J.M., Carter, A., Fins, J.J., Friesen, P., Gallant, J., Huggins, J.E., Illes, J., Kellmeyer, P., Klein, E., Marblestone, A., Mitchell, C., Parens, E., Pham, M., Rubel, A., Sadato, N., Sullivan, L.S., Teicher, M., Wasserman, D., Wexler, A., Whittaker, M., Wolpaw, J. (2017). Four Ethical Priorities for Neurotechnologies and AI. Nature, 551 (7679), 159-163. DOI: 10.1038/551159a.

Zheng, Y., Mao, Y.R., Yuan, T.F., Xu, D.S., Cheng, L.M. (2020). Multimodal Treatment for Spinal Cord Injury: A Sword of Neuroregeneration upon 
Neuromodulation. Neural Regeneration Research, 15 (8), 1437-1450. DOI: 10.4103/1673-5374.274332.

Zhou, J.J., Chen, T., Farber, S.H., Shetter, A.G., Ponce, F.A. (2018). Open-Loop Deep Brain Stimulation for the Treatment of Epilepsy: A Systematic Review of Clinical Outcomes over the Past Decade (2008-present). Neurosurgical Focus, 45 (2), E5. DOI: 10.3171/2018.5.FOCUS18161.

\begin{abstract}
Recent advancements in new neural technologies raise bioethical concerns over personal autonomy, which they potentially threaten to diminish or entirely eliminate. Although caution in the application of deep brain stimulation (DBS) and braincomputer interfaces (BCIs) is explicitly urged in almost every study, the debate features a definitional void as to what notion of autonomy is actually adopted by the authors. The focus on autonomy has dominated the debate to such an extent that other essential values seem to be disappearing from the bioethical horizon, becoming less valued, less important, and less visible. This paper examines the autonomy-problem by probing whether DBS and BCIs indeed threaten personal autonomy. The impact of DBS and BCIs is studied on the examples of several illnesses, whereby the well-being of a person and the importance of informed consent are taken into account to assess the influence of these novel medical technologies on autonomy.
\end{abstract}

\title{
Cytowanie
}

Michałowska, M., Kowalczyk, Ł., Marcinkowska, W., Malicki, M. (2021). Being Outside the Decision-Loop: The Impact of Deep Brain Stimulation and Brain-Computer Interfaces on Autonomy. Analiza i Egzystencja, 56 (4), 25-52. DOI: 10.18276/aie.2021.56-02. 